\title{
Study on satellite altimeter sea state bias estimation comprehensive model
}

\author{
Hong-li Miao ${ }^{1,}$,, Xin Wang ${ }^{1}$, Gui-zhong Wang ${ }^{1}$, Guo-shou Zhang ${ }^{1}$, Jie $_{\text {Zhang }}{ }^{2}$ \\ ${ }^{1}$ College of Information and Engineering, Ocean University of China, Qingdao266100, China; \\ ${ }^{2}$ First Institute of Oceanography, State Oceanic Administration, Qingdao 266061, China; \\ a oumhl@ouc.edu.cn
}

Keywords: satellite altimetry; sea state bias; parametric model; nonparametric model; latitude segmentation

\begin{abstract}
The sea state bias (SSB) is one of the most prominent errors in satellite altimetry. The empirical model was mostly used in practical estimation of SSB, which includes the parametric model and nonparametric model. The estimation of SSB for the global area will result to large deviation with a single model, due to the different distribution of sea condition as well as the different accuracy of the two models. In this paper, two models were applied in regions of different latitude. The results of two models were statistical analyzed and evaluated. The analysis indicate that: the nonparametric model is more effective in the area further north than $30^{\circ} \mathrm{N}$ while the parametric model is more effective in other areas.
\end{abstract}

\section{Introduction}

The satellite altimeter can measure the global sea surface height (SSH) [1] quickly and accurately. Meanwhile, it can obtain important marine remote sensing information, such as significant wave height (SWH) and wind speed (U). The accuracy of altimeter has reached centimeter. At present, the orbit error has been greatly corrected by the development of precision orbit determination. SSB has been the largest source of error for satellite altimetry [2]. Although the value of SSB has reached decimeter, the correction residuals remain of centimeter scale. The empirical model used in practical application includes the parametric model [3] and nonparametric model [4]. When comes to a specialized altimetry mission for the global areas, only a single model was used to estimate the SSB. [5]. However, the two models for different latitude areas have their own advantage in accuracy and extension [6]. Because of the SSB are closely related to SWH and U [7]. The different climate and the sea state of the Northern and Southern Hemispheres account for the great difference of the sea state bias. Therefore, it is necessary to carried out research on the two models for regions of different latitude aiming at develop their respective advantages. A combined comprehensive model will improves the accuracy and extension of the SSB estimation on a global scale.

\section{Global distribution of the sea state}

The subpolar westerlies area is generally located between the latitude $30^{\circ} \sim 60^{\circ}$ in the Northern and Southern Hemispheres. The subpolar westerlies area mainly caused by subtropical high and low pressure belt and has perennial prevalence. Because of the westerlies, the SWH and U usually has larger range in that area. There are more land in the Northern Hemisphere, and most of the belt is irregular due to the influence of the terrain. However, the Southern Hemisphere has less land, the sea area is relatively vast. Thus, the less influenced subpolar westerlies accounts for the large wind speed and significant wave height.

The SWH and U information were extracted from the 106 cycle of Jason-2 altimeter data, and the global distribution map is shown in Fig.1. 


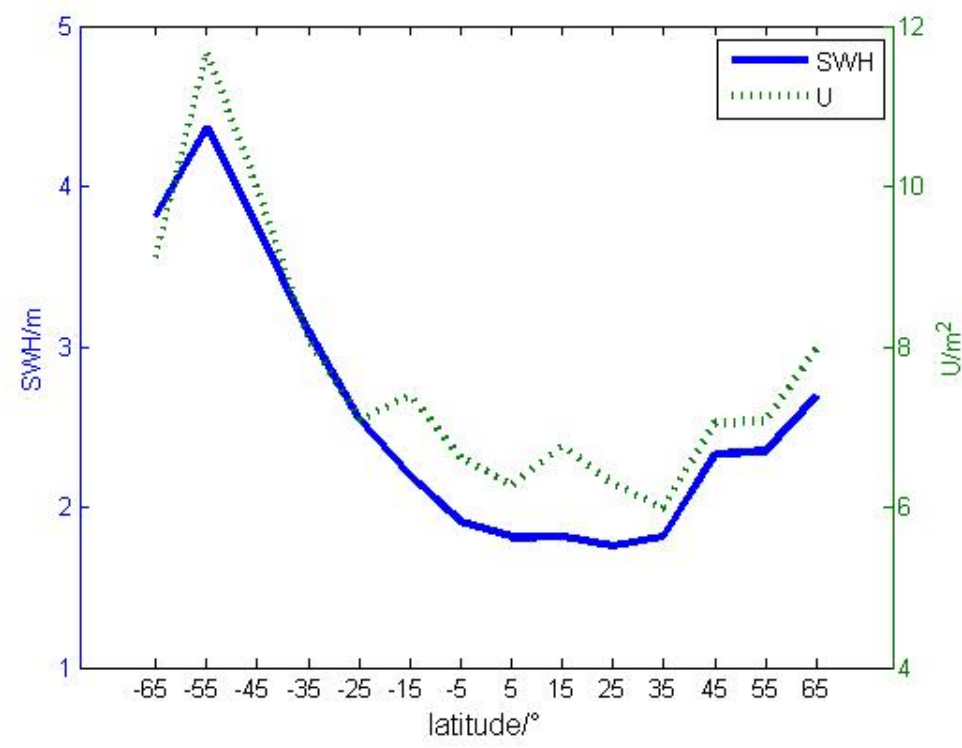

Fig.1. Global zonal distribution of $\overline{S W H}$ and $\bar{U}$

From Figure 1 we can know the SWH and U began to increase from 30 degrees latitude of the Northern and Southern Hemisphere. The SWH or U value in the Southern Hemisphere is larger than the one that in Northern Hemisphere.

\section{Model determination and result analysis}

\section{Model determination.}

The parametric model is based on the second order Taylor expansion of SWH and $U$ and the extension is good. Parametric model can be applied to any SWH and $U$ in normal range. The previous parametric model used the crossover differences of $\mathrm{SSH}, \mathrm{SWH}$, $\mathrm{U}$ to regress the model coefficient. The SSB is not real least squares fitting result. The error of the model coefficient reduces the accuracy of parametric model.

In this paper, an improved parametric model was applied. First the true value of SSB was obtained from direct estimation method [8]. Participating in modeling with the result will reduce the error of model and improve the accuracy of the model.

The final optimized improved parametric model is:

$S S B=S W H[-0.0297624+0.003652763 S W H-0.00251436 U$

$\left.-0.0005458434 S W H^{2}-0.00002327464 U^{2}+0.000350866 S W H \cdot U\right]$

Nonparametric model is based on kernel smoothing estimation method to estimate the SSB. This model does not specify the form of a specific function. To construct weight matrix mass data is needed, and the accuracy of the results is relatively high. However, the modeling process is complex, needs huge computation with low efficiency and bad extension.

Nonparametric model select Gauss kernel function and $\left(h_{U}, h_{S W H}\right)=(2.1 \mathrm{~m} / \mathrm{s}, 0.92 \mathrm{~m})$ as bandwidth value. First calculate the nonparametric SSBA value at crossover points of the rising orbit. Set the value of $U$ and SWH interval $0.25 \mathrm{~m}$ and $0.25 \mathrm{~m} / \mathrm{s}$, respectively. SSB estimation is obtained from the difference between the SSBA and crossover points. The (SWH, U, SSB) query table is built and SSB arbitrary values can be obtained from the bilinear interpolation of the query table.

\section{Model determination.}

This paper uses 10 cycles of data provided by JASON-2 altimeter in 2014. The data covers the latitude between 66 degrees north latitude to 66 degrees south latitude. The parametric model and nonparametric model were both built by using the data set. Latitude interval $20^{\circ}$ division grouping and get the results of the two models respectively in each groups. The result of parametric model is $S S B_{P M}$. The result of nonparametric model is $S S B_{N P}$. The density distribution of the difference 
between the two results was shown in Fig.2 and Fig.3.

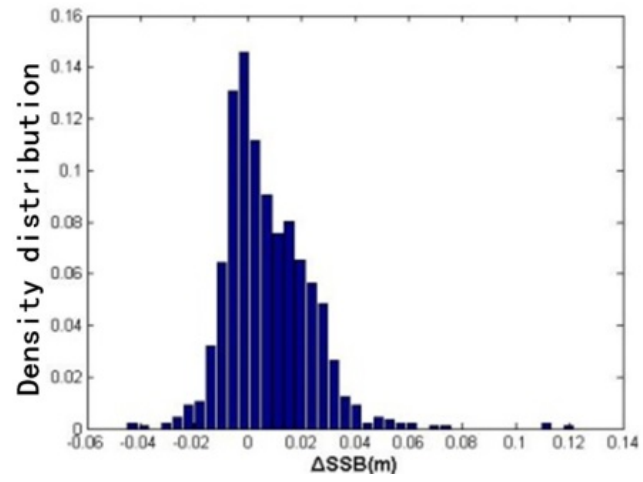

(a)

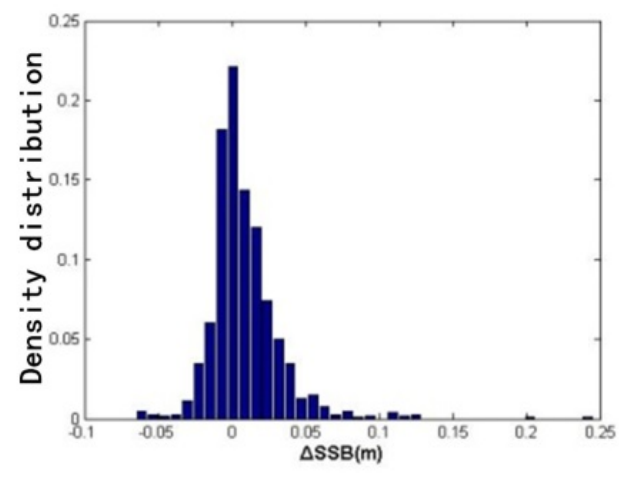

(b)

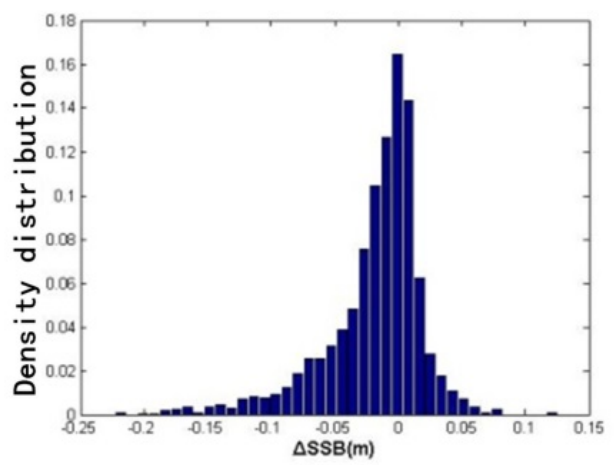

(c)

Fig.2. Density distribution of $\triangle S S B$ in the Northern Hemispheres

(a) $\left(0^{\circ} \sim 20^{\circ}\right)$ (b) $\left(20^{\circ} \sim 40^{\circ}\right)$ (c) $\left(40^{\circ} \sim 67^{\circ}\right)$

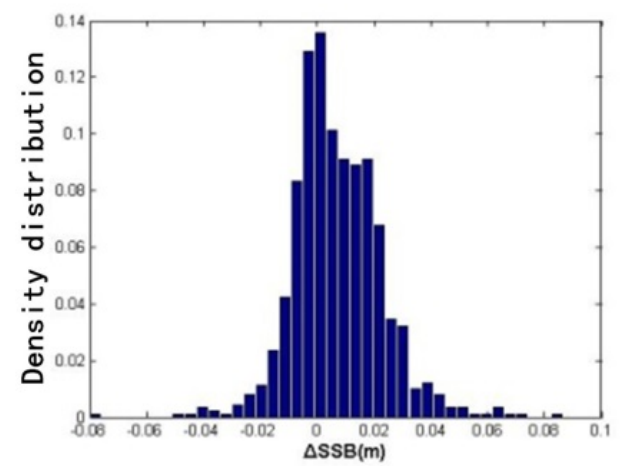

(a)

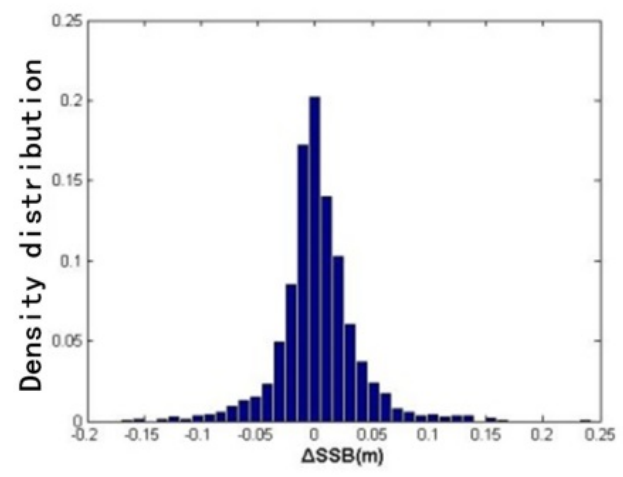

(b)

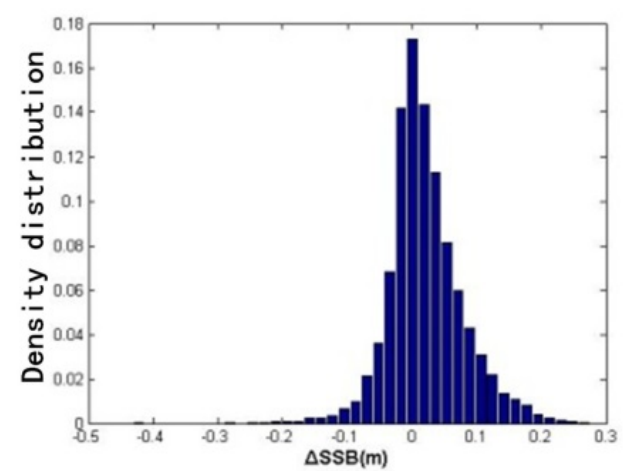

(c)

Fig.3. Density distribution of $\triangle S S B$ in southern hemispheres

(a) $\left(0^{\circ} \sim-20^{\circ}\right)$ (b) $\left(-20^{\circ} \sim-40^{\circ}\right)$ (c) $\left(-40^{\circ} \sim-67^{\circ}\right)$ 
From figure 2 can see that density distribution of $\triangle S S B$ in the northern region is not satisfied normal distribution and the mean is not 0 . Most $\triangle S S B$ in low latitude area are positive and uniform in the middle latitude area while most $\triangle S S B$ in high latitude area are negative. From figure 3 we can see that density distribution in the southern region is also not satisfied normal distribution. Most $\triangle S S B$ in low and high latitude area are positive and uniform between 0 value in the middle latitude area. From figure 2 and figure 3, it can be concluded intuitively that the two results of parametric and nonparametric model are not equal in different area for both northern and southern region. The difference in the north and south latitude region is asymmetry.

Statistical t test prove that there is significant differences in quantitative evaluation or not in each group. The confidence level is $95 \%$, and the critical value of t test was 1.96 . $\mathrm{T}$ absolute values obtained by block segmentation was shown in Table 1.

Table 1. T absolute values of each group

\begin{tabular}{|c|c|c|c|c|c|c|}
\hline & \multicolumn{3}{|c|}{ Northern hemispheres } & \multicolumn{3}{c|}{ Southern hemispheres } \\
\hline Latitude $\left(^{\circ}\right)$ & $0 \sim 20$ & $20 \sim 40$ & $40 \sim 67$ & $0 \sim-20$ & $-20 \sim-40$ & $-40 \sim-67$ \\
\hline T value & 4.3927 & 4.4991 & 10.7783 & 4.8119 & 2.0016 & 23.0916 \\
\hline
\end{tabular}

It can be seen that every $t$ absolute value is larger than the critical value 1.96. It is further demonstrated that there are significant differences between the two models of different latitude areas.

\section{Evaluation and comprehensive application.}

Adopt the coefficient of decision $R_{a}^{2}$ to evaluate model validity.

$$
\begin{aligned}
& R_{a}^{2}=1-\frac{n-1}{n-m-1}\left(1-R^{2}\right) \\
& R^{2}=S S R / S S T
\end{aligned}
$$

$\mathrm{N}$ is the sample number, $\mathrm{m}$ is the variable number, SSR is regression sum of squares and SST is total variation. The goodness of fit to the sample observation value of the regression model can be evaluated by $R_{a}^{2}$. The part of SST can be explained the model results is larger when the $R_{a}^{2}$ is larger. The two model's goodness of fit is better. $R_{a}^{2}$ values of each group are shown in table 2 , and the distribution curve is shown in figure 4 (PM and NP are short for parametric and nonparametric):

Table $2 R_{a}^{2}$ values of each group

\begin{tabular}{|c|c|c|c|c|c|c|}
\hline & \multicolumn{3}{|c|}{ Northern Hemispheres } & \multicolumn{3}{c|}{ Southern Hemispheres } \\
\hline Latitude $\left.^{\circ}\right)$ & $0 \sim 20$ & $20 \sim 40$ & $40 \sim 67$ & $0 \sim-20$ & $-20 \sim-40$ & $-40 \sim-67$ \\
\hline$R_{a_{(\mathrm{PM})}^{2}}$ & 0.3096 & 0.3075 & 0.3229 & 0.2917 & 0.3140 & 0.3645 \\
\hline$R_{a}^{2}(\mathrm{NP})$ & 0.2473 & 0.3379 & 0.3503 & 0.2521 & 0.3091 & 0.3664 \\
\hline
\end{tabular}

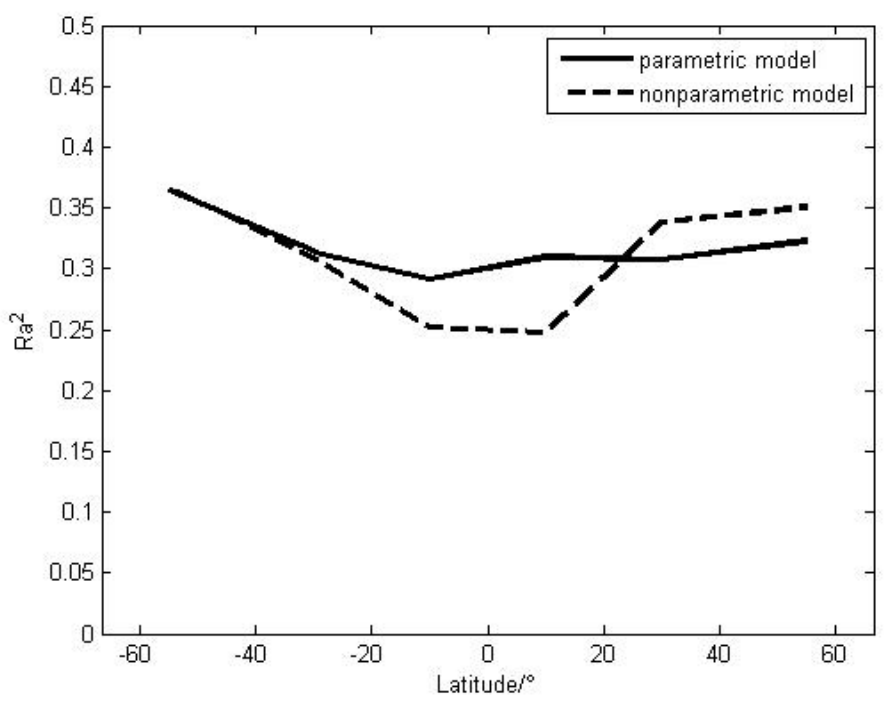

Fig.4.The distribution curve of $R_{a}^{2}$ 
From table 2 and figure 4 can be seen, above $30^{\circ}$ north latitude the nonparametric model result is larger than parametric model results. The nonparametric model is more effective in this area while parametric model is more effective in other areas.

\section{Conclusion}

This paper that divided the data into each bin interval is $20^{\circ}$ latitude areas, then estimate the SSB by the improved parametric model and nonparametric model in different areas respectively. Analysis show that there are significant differences between the two results of different models are different from $t$ test and the density distribution of $\triangle S S B$. Through goodness of fit test and compute the coefficient of decision of different model results in different areas. And then make quantitative evaluation of the validity of the model give the conclusion: The nonparametric model is more effective in the area above $30^{\circ}$ north latitude and the parametric model is effective and efficiency in the other areas. The comprehensive application of two kinds of empirical models in the whole latitude region is realized.

\section{Acknowledgements}

This work was supported by the Natural Science Foundation of China (Grant No. 41176157 and 41406197).

\section{References}

[1] Lee-Lueng Fu, Anny Cazenave. Satellite Altimetry and Earth Sciences[M]. San Diego: ACADEMIC Press , 2001:1-4

[2] Labroue S, Gaspar P, J Dorandeu, Zanife O Z, et al. Non parametric estimates of the sea state bias for the JASON-1 radar altimeter [J]. Marine Geodesy 2004, 27 (3-4): 453-481.

[3] Gaspar P, Ogor F, Le Traon P-Y et al. Estimating The Sea State Bias of the TOPEX and POSEIDON Altimeters from Crossover Differences[J]. J. Geophys. Res., 1994, 99(C12): 24981-24994.

[4] Gaspar P, Florens JP. Estimation of the sea state bias in radar altimeter easurements of sea level: Results from a new nonparametric method[J] .J.Geophys.Res.,1998,103(C8):15803-15814.

[5] Gaspar P, Labroue S, Ogor L.et al. Improving nonparametric estimates of the sea state bias in radar altimeter measurements of sea level[J]. J. Atmos. Oceanic Technol.,2002,19: 1690-1707.

[6] Labroue S, Gaspar P, Dorandeu J. et al. Nonparametric Estimates of the Sea State Bias for the JASON-1 Radar Altimeter[J]. Marine Geodesy, 2004, 27: 453-481.

[7] Chelton DB. The sea state bias in altimeter estimates of sea level from collinear analysis of TOPEX data[J]. J. Geophys. Res., 1994, 99(C12): 24,995-25,008.

[8] Vabdemark D, Tran N, Beckley. et al. Direct estimation of sea state impacts on radar altimeter sea level measurements[J]. Geophysical Research Letters, 2002, 29(24): 48-52. 